\title{
The Effect of Light-Emitting Diode Light on the Physical Traits of Chicks
}

\author{
Etimad Alattar ${ }^{1}$, Khitam Elwasife'2, Eqbal Radwan ${ }^{1 *}$ \\ ${ }^{1}$ Biology Department, Faculty of Science, Islamic University of Gaza, Gaza, Palestine \\ ${ }^{2}$ Physics Department, Faculty of Science, Islamic University of Gaza, Gaza, Palestine \\ Email: *ERNP2030@gmail.com
}

How to cite this paper: Alattar, E., Elwasife, K. and Radwan, E. (2019) The Effect of Light-Emitting Diode Light on the Physical Traits of Chicks. Open Journal of Animal Sciences, 9, 481-491.

https://doi.org/10.4236/ojas.2019.94037

Received: September 25, 2019

Accepted: October 28, 2019

Published: October 31, 2019

Copyright $\odot 2019$ by author(s) and Scientific Research Publishing Inc. This work is licensed under the Creative Commons Attribution International License (CC BY 4.0).

http://creativecommons.org/licenses/by/4.0/

\begin{abstract}
Environmental conditions including light are considered a critical element of chicks well-being. The aim of the present study was to investigate the effect of LED light on the physical traits of chicks. We took forty-one-day-old chicks and randomly separated it into two groups. The chicks in the first group were reared under the effect of incandescent lamp light and in the second one were under the effect of white LED lighting. Chicks were daily monitored for individual chick body, weight gain, feed intake, feather color and fear responses. The distance between chicks and source of light was $50 \mathrm{~cm}$. Student's t-test test was used for statistical evaluation at $p<0.05$ level. The results of the current study showed that chicks reared under incandescent light bulb had significantly higher body weight compared with chicks reared under LED light. The magnitude of body weight in LED group was lower (1192.75 $\pm 149.9 \mathrm{~g}$ ) compared to incandescent light group $(1307.75 \pm 110.5 \mathrm{~g})$. The obtained results revealed that LED light reared chicks were more active; it showed long mobility duration and high levels of exploration in the farm as compared to those in incandescent light group. The results also indicated that incandescent light chicks were less fearful than LED chicks. Furthermore, the study showed that LED light reared chicks have pale pink combs and white feathers that cover all over the body. On the other hand, incandescent light reared chicks have dark red combs and whitish-yellow feathers that cover certain areas of the body especially chick wings, tail and head.
\end{abstract}

\section{Keywords}

Light Emitting Diode, Incandescent Bulb, Fear Response, Physical Traits, Tonic Immobility Test

\section{Introduction}

Environmental conditions including light are considered a critical element of 
chicks well-being. Lighting is a powerful factor in chicks growth [1] as producers want to provide appropriate culturing conditions, such as ventilation, humidity, temperature and illumination, for chicks to reach their full optimum growth. Another major factors such as light source type, light intensity, organization of the photoperiod (light-dark cycles), and the wavelength of light are all worth considering [2]. Furthermore, it has been found out that light manipulation has been an effective measure to improve chick production [1] [3]. Light affects production efficiency, welfare, growth rate and performance, chicks' vision and modulation of physiological condition, behavior and immune response [1] [4] [5] [6] [7].

Conventionally, incandescent (ICD) bulbs are used in chick houses as lighting source, which is less energy efficient and substantially increases the cost of production due to the high cost of electricity [8]. The use of light emitting diode (LED) has become considerably more attractive because of its vast potential for commercial application [3] [9]. In addition LEDs have lower electricity consumption, smaller size and volume, wavelength specificity, longer durability, safety, provide adequate illumination, low maintenance costs and less heat generation when compared to incandescent lamps [5] [10] [11].

LED is a unique type of semiconductor diode [2]. The wavelength of the light emitted depends on the properties of semiconductor material [12]. LEDs can peak emission wavelengths from $250 \mathrm{~nm}$ to $1000 \mathrm{~nm}$. The effect of LED light on living organisms has been studied over the last years and increasingly so in recent years. There has been a significant amount of research on the effects of fluorescent and incandescent light bulb on growth, performance and production of chicks, but very little research on the effects of LED light on their behavior and physical characteristics. However, the impact of light conditions, especially LED is potentially profound. Previous studies have shown possible effects in chicks' performance under lighting by LED light [1] [2] [7]. Meanwhile, most researcher have focused on the performance, but relatively little attention has been given to the physical traits of chicks. However, there is a lack of studies on the effect of LED light on the physical traits of the chicks. Therefore, the present experiment was designed to discover the effect of light conditions produced by LED on their physical traits such as behaviour, type and color of feather, length, volume and weight of body, comb color, vitality and fear responses. Since experiments on humans are very difficult, chicks would be a better choice to study the overall effect of LED light on their overall physical traits.

\section{Method}

The experimental procedures employed in this study were in accordance with the standard animal welfare guideline set out by the Ministry of Agriculture (Resposible authority of animal production at Palestine). This study was carried out in May 2018 for 4 weeks in a private poultry farm in Gaza governorate, Gaza Strip, Palestine. 
A total of 40 one-day-old chicks with an average weight of $42.3 \pm 1.76 \mathrm{~g}$ were purchased from a local commercial hatchery and subjected to the study. The chicks were randomly classified into two identical sets of 20 chicks each. The first group was kept under the normal condition, in other words, the farm was illuminated using ICD light (control group). The second group was kept under the conditions of the effect of white LED light (experimental group). All chicks were housed in the farm under natural conditions of humidity and temperature. The chicks were fed a diet (Ambar Company, Israel) from one to 28 days of age. The diets (as recommended by Ministry of Agriculture) were similar for two treatment groups. The chicks in two groups had free access to feed and water at all times. The chicks farm was supplied with sufficient water, feed and natural ventilation, and was regularly cleaned and disinfected. All factors except for light were kept constant throughout the whole experiment.

This experiment involved two treatments: ICD light bulb (3200 K), and white LED light lamp $(6500 \mathrm{~K})$. Artificial light was the only light source in the rearing rooms. The LED system consisted of LED sticks and a panel (18.5 length $\mathrm{cm} \times$ 13 wide $\mathrm{cm}$ ) for setting the sticks. The light source was placed $50 \mathrm{~cm}$ above the chicks. The electric power of the ICD and LED light was measured as 60 and 15 Watt respectively. These values were chosen based on the common normal condition used by the farmers in our country.

Behavior of the targeted chicks was consecutively observed every day. The main physical traits of chicks were recorded weekly. On Day 28, the physical traits of the chicks were investigated by measuring weight of body, type and color of feather, comb color, vitality and activity (evaluate by long observations of walking and sitting of target chicks), as well as fear response. Fear was assessed by determining tonic immobility time. On Day 28 , a tonic immobility test was carried out on 10 chicks from each group. Each chick was carefully handled, transferred to a separate room and held for $10 \mathrm{~s}$ to induce tonic immobility and then released. After this time, if tonic immobility lasted less than $10 \mathrm{~s}$, the process was immediately repeated. When tonic immobility lasted more than 10 $s$, the total duration of tonic immobility was recorded, with a maximum duration of $600 \mathrm{~s}$ according to Jones [13].

All data were analyzed with the Statistical Package for Social Sciences, 22.0 (SPSS for Windows; SPSS Inc, Chicago, IL, USA). Graphs were plotted using Microsoft Excel program version 2010. Data are presented as the mean \pm SD and means were compared by two-tailed Student's t-test. When the $\mathrm{p}$ value was less than 0.05 , the statistical test was determined as statistically significant.

\section{Results}

The overall effect of LED light in comparison with ICD light on physical traits of chicks is presented. During the study period, LED showed an effect on body weight in comparison with ICD light. Differences were observed between two groups, chicks of LED group had lower body weight/week than chicks in ICD 
group (Figure 1). At the end of the experiment, the results showed that chicks' weight was significantly higher $(p=0.009)$ in the chicks reared under ICD light than the chicks reared under LED light. This trend continued to 28 days of age.

Table 1 illustrates chicks' weight (Mean \pm SD) at the end of the experiment. As clearly shown, there was significant difference in chicks weight between the two groups, chicks reared under ICD light were significantly heavier than those reared under LED light at the age of 28 days.

In the current work, we observed that LED light reduced the length and volume of chicks as compared to ICD group. The activity behaviour was also influenced by the LED light. By observing the behavior of chicks over 28 days it was found that LED light reared chicks were more active, it showed long mobility duration and high levels of exploration in the farm as compared to those chicks reared under ICD light. Therefore, LED light did stimulate the movement and activity of chicks.

As clearly shown in Table 2, we observed that food intake changed with the growth of the chicks, such that, in LED group, food intake increased throughout the experimental period. Chicks in LED group consumed the highest amount of food compared with chicks in ICD group. At the age of 28 days, chicks exposed to ICD light ate less food than chicks exposed to LED light.

The results also indicated that LED light reared chicks have pale pink combs and white feathers that cover all over the body (Figure 2). On the other hand, chicks reared under ICD light have dark red combs and whitish-yellow feathers

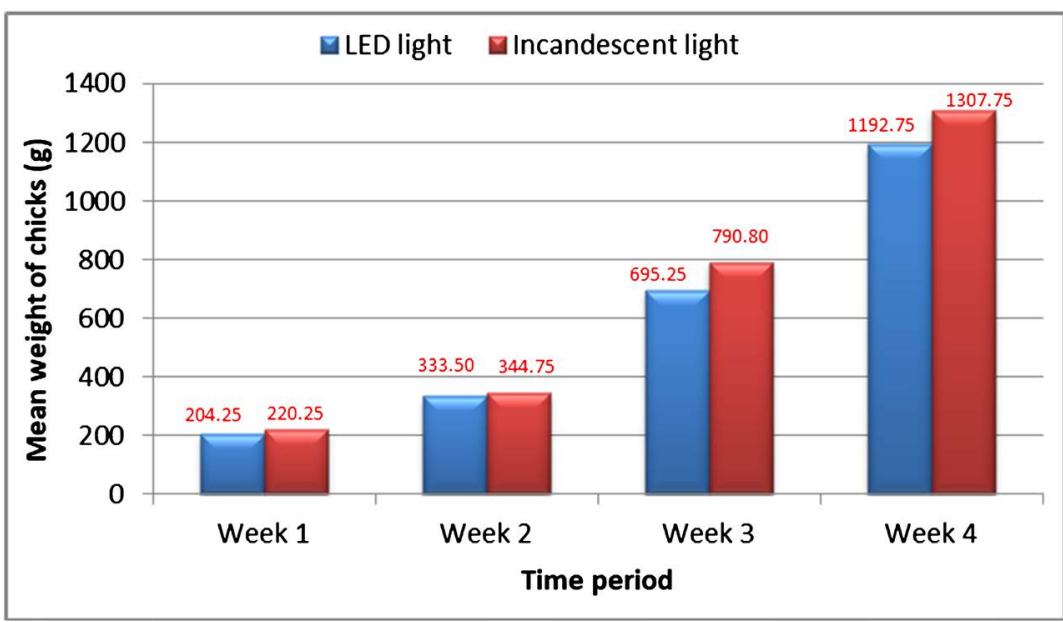

Figure 1. The average of body weight per week for chicks under the effect of ICD and LED light.

Table 1. The average of weight (g) of chicks for control and treated group at day 28 .

\begin{tabular}{cccc}
\hline Experimental Group & Mean & SD & $p$-Value \\
\hline ICD light & 1307.75 & 110.56 & $0.009^{1}$ \\
LED light & 1192.75 & 149.95 & \\
\hline
\end{tabular}

${ }^{1} p$ is highly significant at the 0.05 level. 
Table 2. The physical traits of chicks as affected by LED and ICD treatment.

\begin{tabular}{ccc}
\hline \multirow{2}{*}{ Traits } & \multicolumn{2}{c}{ Groups } \\
\cline { 2 - 3 } & Group I (ICD light) & Group II (LED light) \\
\hline Chick weight $(\mathrm{g})$ & More & Less \\
Chick length $(\mathrm{cm})$ & More & Less \\
Chick volume & More & Less \\
Fear response & Less & More \\
Tonic immobility & Less & More \\
Activity and vitality & Less & More \\
Feather color & whitish-yellow & Clear white \\
Feathers type & Fluffy feather & Quill feather \\
Feathers distribution & Wings, tail and head & All over the chick body \\
Comb color & Deep red & Pale pink or bright red \\
Food intake & Less & More \\
\hline
\end{tabular}
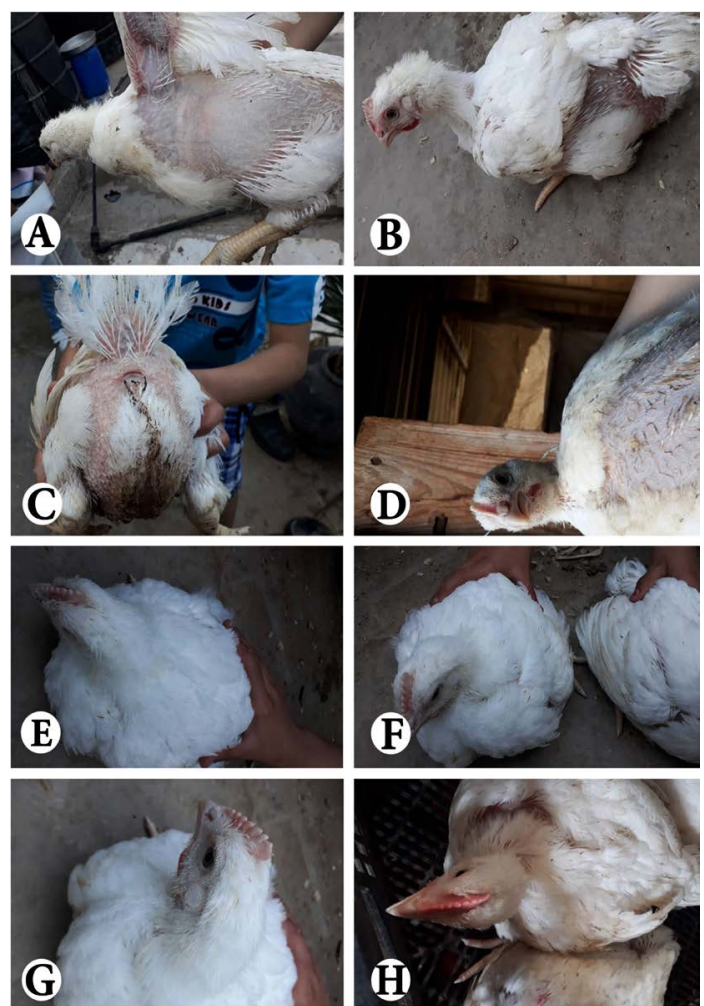

Figure 2. The effect of LED and ICD light on chicks: (A), (B), (C) and (D) color and distribution of feather for ICD light reared chicks, (E) and (F) for LED light reared chicks, $(\mathrm{G})$ and $(\mathrm{H})$ comb color for LED and ICD light reared chicks respectively.

that cover certain areas of the body especially chick wings, tail and head. As reflected from Figure 2, LED showed an influence on type of feather in comparison with ICD light. The results indicated that chicks exposed to ICD light have fluffy feathers, whereas LED light reared chicks have quill feathers. 
Table 3. The average of tonic immobility (s) of chicks for control and treated group.

\begin{tabular}{ccc}
\hline Experimental Group & Mean & $p$-Value \\
\hline ICD light & 234 & $0.001^{1}$ \\
LED light & 588 & \\
\hline
\end{tabular}

${ }^{1} p$ is highly significant at the 0.05 level.

As revealed in Table 3, there was a significant difference $(p<0.001)$ in tonic immobility duration between the LED and ICD groups. The duration of tonic immobility, a response which increases with fearfulness, was much longer in chicks reared LED light. On the other hand, chicks reared under ICD light showed lower tonic immobility, means that ICD light reared chicks were less fearful than LED chicks. Therefore, it suggests that LED light would increase the fear responses of chicks.

\section{Discussion}

In this study, we sought to investigate the physical traits of chicks and were compared to control when they were exposed to LED light. In this experiment, significant difference was observed for the day-old body weight among each group. Chicks weight in LED group was found to be significantly lower than the ICD light group. The results of the present study were consistent with the results of Rozenboim et al. [14], they reported that under ICD light, the body weight of birds was significantly higher than under fluorescent lamps at 19 and 42 day of age. In the studies of Mohamed et al. [2], Rozenboim et al. [15], Rozenboim et al. [16], Cao et al. [17], Cao et al. [18] and Kim et al. [19] they showed that body weight of broiler was influenced by LED light. The improvement of final body weight in chicks reared under ICD light may be attributed to the higher proliferation of skeletal muscle satellite cells [20] or calming effect of ICD light where birds become less active [21] and less stressful [22].

On the contrary, the results disagree with that of Olanrewaju et al. [6], they carried out an experiment to compare the effects of LED light bulbs, especially cool LED light bulbs along with warm LED and ICD light bulbs, on growth performance of broilers. They showed that cool LED showed an effect on body weight in comparison with ICD light bulbs. There was no significant difference between LED light bulbs examined in this study. In addition, there was no difference between ICD and LED light bulbs in their effect on body weight. Leighton et al. [23] reported that ICD light may be replaced with energy-efficient light sources without adverse effects on broiler growth performance. In the study of Petek et al. [24], they found that the effect of LED and ICD light bulbs on body weight was not statistically significant. Different results have also been reported by Kumar et al. [25]. They demonstrated that average body weight of broiler was numerically higher in LED light treatment groups as compared to ICD light group.

The results further indicated that, under LED light, chicks were more active, it 
showed long mobility duration and high levels of exploration in the farm as well as they spent less time sitting as compared to those in ICD light group. The walking behaviour appeared to be enhanced by LED light whereby ICD light decreased walking behaviour and increased the sitting behaviour of chicks. The results are in accordance with that observed by Huth and Archer [26], they revealed that providing LED light during incubation can improve weight of chicks. These improvements mainly related to the physiological and metabolic responses to light during embryonic development. In addition, we hypothesized that the activity of chicks may be related with their size as mentioned in the study of Sultana et al. [5], they documented that the decreasing of chicks movement may be due to an increase its body size.

Although the fear response is difficult to assess, Jones and Faure [27] have developed a test known as tonic immobility which has considered the most common measure of fear in poultry [28] and widely used to study fear responses of birds [29]. In our experiment, chicks reared under LED light showed higher tonic immobility than that under ICD light group. Our results illustrated that LED light influenced the fear response of chicks, where LED light would increase the fear responses of chicks. Different results were previously reported in the study of Archer [3]. He demonstrated that raising broilers under LED lights can reduce their fear.

With regard to the feeding, the results revealed that feeding intake was slightly increased under LED light group as compared to ICD light group. A similar finding was previously stated in the study of Kumar et al. [25] and Sharideh and Zaghari [30], they mentioned that feed intake was highest in birds reared under white light compared to ICD light bulbs. The reasons standing behind altering feed intake in treated chicks were found to be similar to the reasons mentioned by other studies [24]. They pointed out that increased feed intake in LED group may be due to increased activity and movement of chicks during the photoperiod [9]. On the contrary, the result for feeding intake was not consistent with the findings of Baxter and Bédécarrats [31], they showed that birds under ICD light had significantly higher feed intake than under red LED light.

As indicated above, the color of the comb appears to be affected by LED light. The comb is an ornamental organ in chicks which can be used as an indicator of health [32], cell-mediated immunity [33] and also an indicator of health status disease resistance and nutritional status in the flock [34]. The findings showed that ICD chicks have redder combs than the LED chicks. We also noticed that, in the case of LED chicks, their combs are a very pale pink color. The reasons standing behind the changed color of combs were found to be similar to the reasons reported by other studies [33] [35]. They mentioned that red grouse with redder combs have more carotenoid pigmentation and circulating carotenoids, and as found in several other bird species [36]. The carotenoid-based coloration of red grouse combs might directly signal cell-mediated immunity and male health because of the immuno-stimulatory action of ingested and circulated carotenoid pigments. Kimball and Braun [37] mentioned that the red color 
of the comb is due to the presence of blood in the underlying capillary sinuses. Also, Mougeot [33] predicted that redder combs would indicate a greater cellular immune response. In male red grouse, he found that $\mathrm{T}$-cell-mediated immune responsiveness could be well predicted from comb characteristics, and in particular from comb redness, which is due to carotenoid pigmentation [38]. Comb colour might reflect ability to cope with stress and its ability to raise an immune response to a standardized challenge such as parasite infestation [33] [39] [40].

According to Stettenheim [41], the deep red color of combs of the LED chicks has been thought to result from the influx of blood (hemoglobin in particular) into the highly vascularized dermal layer of the skin. According to Peeps [42], he reported that pale pink combs can indicate sickness or disease. This finding is in agreement with previous evidence of relationship between blood properties and LED light [42]. In their study, they evaluate the effect of LED on blood microcirculation during chronic wound healing in diabetic and non-diabetic patients. A significant increase in blood flow was noted in the treated group, while there was no difference in the control groups.

\section{Acknowledgements}

The authors thankfully acknowledge the staff of the Department of Biology and Physics at the Islamic University of Gaza, for providing necessary support to conduct this experiment.

\section{Conflicts of Interest}

The authors declare no conflicts of interest regarding the publication of this paper.

\section{References}

[1] Leigh, M.B., McFadden, T.B., Schumacher, L. and Firman, J.D. (2017) Efficacy of Various Wavelengths of Monochromatic Light Emitting Diode Illumination on Growth and Performance of Broiler Chickens. International Journal of Poultry Science, 16, 475-480. https://doi.org/10.3923/ijps.2017.475.480

[2] Mohamed, R.A., El-Kholya, S.Z., Shukry, M., El-Kassas, S. and El Saidy, N. (2017) Manipulation of Broiler Growth Performance, Physiological and Fear Responses Using Three Monochromatic LED Lights. Alexandria Journal for Veterinary Sciences, 53, 57-62. https://doi.org/10.5455/ajvs.263048

[3] Archer, G.S. (2018) Color Temperature of Light-Emitting Diode Lighting Matters for Optimum Growth and Welfare of Broiler Chickens. Animal, 12, 1015-1021. https://doi.org/10.1017/S1751731117002361

[4] Xie, D., Wang, Z.X., Dong, Y.L., Cao, J., Wang, J.F., Chen, J.L. and Chen, Y.X. (2008) Effects of Monochromatic Light on Immune Response of Broilers. Poultry Science, 87, 1535-1539. https://doi.org/10.3382/ps.2007-00317

[5] Sultana, S., Hassan, M.D., Choe, H.S. and Ryu, K.S. (2013) The Effect of Monochromatic and Mixed LED Light Colour on the Behaviour and Fear Responses of Broiler Chicken. Avian Biology Research, 6, 207-214. https://doi.org/10.3184/175815513X13739879772128 
[6] Olanrewaju, H., Purswell, J.L. and Collier, S.D. (2015) Effects of Color Temperatures (Kelvin) of LED Bulbs on Growth Performance, Carcass Characteristics and Ocular Development Indices of Broilers Grown to Heavy Weights. Poultry Science, 17, 338-344. https://doi.org/10.3382/ps/peu082

[7] Liu, K., Xin, H. and Chai, I. (2017) Choice between LED and Fluorescent Lights by Pullets and Laying Hens. Annual International Meeting, American Society of Agricultural and Biological Engineers (ASABE), Spokane, Washington, 16-19 July 2017, Paper No. 1700029. https://doi.org/10.13031/aim.201700029

[8] Pereira, P.A., Yanagi Junior, T., Silva, J.P., Lima, R.R., Campos, A.T. and Abreu, L.H. (2012) Technical Evaluation of Artificial Lighting Systems for Broiler Houses. Engenharia Agrícola, 32, 1011-1024. https://doi.org/10.1590/S0100-69162012000600002

[9] Purswell, J.L., Olanrewaju, H.A. and Linhoss, J.E. (2018) Effect of Light Intensity Adjusted for Species-Specific Spectral Sensitivity on Live Performance and Processing Yield of Male Broiler Chickens. The Journal of Applied Poultry Research, 27, 570-576. https://doi.org/10.3382/japr/pfy034

[10] Bello-Bello, J.J., Martínez-Estrada, E., Caamal-Velázquez, J.H. and Morales-Ramos, V. (2016) Effect of LED Light Quality on in Vitro Shoot Proliferation and Growth of Vanilla (Vanilla planifolia Andrews). African Journal of Biotechnology, 15, 272-277. https://doi.org/10.5897/AJB2015.14662

[11] Jiang, N., Grundy, S., Bian, Z. and Lu, C. (2017) Investigation of LED Light Effects on Plant Growth in Improved Protected Horticulture System. In: Greensys-International Symposium on New Technologies for Environment Control, Energy-Saving and Crop Production in Greenhouse and Plant Factory, Beijing, China, 20-24 August 2017.

[12] Olle, M. and Virsile, A. (2013) The Effect of Light Emitting Diode Lighting on Greenhouse Plant Growth and Quality. Agricultural and Food Science, 22, 223-234. https://doi.org/10.23986/afsci.7897

[13] Jones, R.B. (1996) Fear and Adaptability in Poultry: Insights, Implications and Imperatives. World s Poultry Science Journal, 52, 131-174. https://doi.org/10.1079/WPS19960013

[14] Rozenboim, I., Robinzon, B. and Rosenstrauch, A. (1999) Effect of Light Source and Regimen on Growing Broilers. British Poultry Science, 40, 452-457. https://doi.org/10.1080/00071669987197

[15] Rozenboim, I., Biran, I., Uni, Z., Robinzon, B. and Halevy, O. (1999) The Effect of Monochromatic Light on Broiler Growth and Development. Poultry Science, 78, 135-138. https://doi.org/10.1093/ps/78.1.135

[16] Rozenboim, I., Biran, I., Chaiseha, Y., Yahav, S., Rosentrauch, A., Sklan, D. and Halevy, O. (2004) The Effect of a Green and Blue Monochromatic Light Combination on Broiler Growth and Development. Poultry Science, 83, 842-845.

https://doi.org/10.1093/ps/83.5.842

[17] Cao, J., Wang, Z. and Chen, Y. (2008) Green and Blue Monochromatic lights Promote Growth and Development of Broilers via Stimulating Testosterone Secretion and Myofiber Growth. Journal of Applied Poultry Research, 17, 211-218. https://doi.org/10.3382/japr.2007-00043

[18] Cao, J., Wang, Z., Dong, Y., Zhang, Z., Li, J., Li, F. and Chen, Y. (2012) Effect of Combinations of Monochromatic Lights on Growth and Productive Performance of Broilers. Poultry Science, 91, 3013-3018. https://doi.org/10.3382/ps.2012-02413

[19] Kim, M.J., Parvin, R. and Choi, H.C. (2013) Growth Performance and Hematologi- 
cal Traits of Broiler Chickens Reared under Monochromatic Light Source. Poultry Science, 92, 1461-1466. https://doi.org/10.3382/ps.2012-02945

[20] Halevy, O., Piestun, Y., Rozenboim, I. and Reuveni, Z.Y. (2006) In Ovo Exposure to Monochromatic Green Light Promotes Skeletal Muscle Cell Proliferation and Affects Myofiber Growth in Posthatch Chicks. American Journal of Physiology-Regulatory, Integrative and Comparative Physiology, 290, R1062-R1070. https://doi.org/10.1152/ajpregu.00378.2005

[21] Mohamed, R.A., Eltholth, M.M. and El-Saidy, N.R. (2014) Rearing Broiler Chickens under Monochromatic Blue Light Improve Performance and Reduce Fear and Stress during Pre-Slaughter Handling and Transportation. Biotechnology in Animal Husbandry, 30, 457-471. https://doi.org/10.2298/BAH1403457M

[22] Mohamed, R.A., Abou-Ismail, U.A. and Shukry, M. (2016) Effects of Different Monochromatic LED Light Colours on Fear Reactions and Physiological Responses in Mulard Ducks. Animal Production Science, 57, 1128-1136.

https://doi.org/10.1071/AN15249

[23] Leighton, A.T., Hulet, R.M. and Denbow, D.M. (1989) Effect of Light Sources and Light Intensity on Growth Performance and Behaviour of Male Turkeys. British poultry science, 30, 563-574. https://doi.org/10.1080/00071668908417180

[24] Petek, M., Orman, A., Dikmen, S. and Alpay, F. (2010) Physical Chick Parameters and Effects on Growth Performance in Broiler. Archives Animal Breeding, 53, 108-115. https://doi.org/10.5194/aab-53-108-2010

[25] Kumar, S., Gupta, R.K., Sharma, A., Singh, Y., Mehta, N. and Kashyap, N. (2017) Performance and Carcass Characteristics of Broiler Chickens Reared under Light Emitting Diodes (LEDs) Light VIS-a-VIS Incandescent Light Supplemental Lighting Programme. Journal of Animal Research, 7, 1157-1163. https://doi.org/10.5958/2277-940X.2017.00173.5

[26] Huth, J.C. and Archer, G.S. (2015) Effects of LED Lighting during Incubation on Layer and Broiler Hatchability, Chick Quality, Stress Susceptibility and Post-Hatch Growth. Poultry Science, 94, 3052-3058. https://doi.org/10.3382/ps/pev298

[27] Jones, R.B. and Faure, J.M. (1981) Sex and Strain Comparisons of Tonic Immobility (Righting Time) in the Domestic Fowl and the Effect of Various Methods of Induction. Behavioural Processes, 6, 47-55. https://doi.org/10.1016/0376-6357(81)90015-2

[28] Huth, J.C. and Archer, G.S. (2015) Comparison of Two LED Light Bulbs to a Dimmable CFL and Their Effects on Broiler Chicken Growth, Stress and Fear. Poultry Science, 94, 2027-2036. https://doi.org/10.3382/ps/pev215

[29] Mills, A.D. and Faure, J.M. (1986) The Estimation of Fear in Domestic Quail: Correlations between Various Methods and Measures. Biology of Behaviour, 11, 235-243.

[30] Sharideh, H. and Zaghari, M. (2017) Effect of Light Emitting Diodes with Different Color Temperatures on Immune Responses and Growth Performance of Male Broiler. Annals of Animal Science, 17, 545-553. https://doi.org/10.1515/aoas-2016-0073

[31] Baxter, M. and Bédécarrats, G. (2014) Evaluating the Effect of Various Light Sources on Reproductive and Growth Parameter in Laying Hens. Abstracts of the 2014 International Poultry Scientific Forum Atlanta, Georgia. Poultry Science, 93, 99.

[32] Mukhtar, N. and Khan, S.H. (2012) Comb: An Important Reliable Visual Ornamental Trait for Selection in Chickens. World's Poultry Science Journal, 68, 425-434. 
[33] Mougeot, F. (2008) Ornamental Comb Colour Predicts T-Cell-Mediated Immunity in Male Red Grouse Lagopus lagopus scoticus. Naturwissenschaften, 95, 125-132. https://doi.org/10.1007/s00114-007-0303-6

[34] Johnson, K., Thornhill, R., Ligon, J.D. and Zuk, M. (1993) The Direction of Mothers' and Daughters' Preferences and the Heritability of Male Ornaments in Red Jungle Fowl (Gallus gallus). Behavioral Ecology, 4, 254-259. https://doi.org/10.1093/beheco/4.3.254

[35] Martinez-Padilla, J., Mougeot, F., Perez-Rodriguez, L. and Bortolotti, G.R. (2007) Nematode Parasites Reduce Carotenoid-Based Signalling in Male Red Grouse. Biology Letters, 3, 161-164. https://doi.org/10.1098/rsbl.2006.0593

[36] McGraw, K.J. and Klasing, K.C. (2006) Carotenoids, Immunity and Integumentary Coloration in Red Junglefowl (Gallus gallus). The Auk, 123, 1161-1171.

https://doi.org/10.1093/auk/123.4.1161

[37] Kimball, R.T. and Braun, E.L. (2008) A Multigene Phylogeny of Galliformes Supports a Single Origin of Erectile Ability in Non-Feathered Facial Traits. Journal of Avian Biology, 39, 438-445. https://doi.org/10.1111/j.0908-8857.2008.04270.x

[38] Mougeot, F., Martinez-Padilla, J., Pérez-Rodríguez, L. and Bortolotti, G.R. (2007) Carotenoid-Based Coloration and Ultraviolet Reflectance of the Sexual Ornaments of Grouse. Behavioral Ecology and Sociobiology, 61, 741-751. https://doi.org/10.1007/s00265-006-0304-Z

[39] Mougeot, F., Perez-Rodriguez, L., Martinez-Padilla, J., Leckie, F. and Redpath, S.M. (2007) Parasites, Testosterone and Honest Carotenoid-Based Signalling of Health. Functional Ecology, 21, 886-898. https://doi.org/10.1111/j.1365-2435.2007.01302.x

[40] Yang, C., Wang, J., Fang, Y. and Sun, Y.H. (2013) Is Sexual Ornamentation an Honest Signal of Male Quality in the Chinese Grouse (Tetrastes Sewerzowi)? PLoS ONE, 8, e82972. https://doi.org/10.1371/journal.pone.0082972

[41] Stettenheim, P.R. (2000) The Integumentary Morphology of Modern Birds-An Overview. American Zoologist, 40, 461-477. https://doi.org/10.1093/icb/40.4.461

[42] Peeps, M., (2016) What a Chicken's Comb Can Indicate. https://www.backyardchickens.com/articles/what-a-chickens-comb-can-indicate.72 $\underline{202 /}$ 